\title{
CAPTURED DISCOURSE, CAPTURED LIVES
}

\author{
Colin Johnson
}

The translation from speech to writing, especially writing considered suitable for public consumption, involves editing which is massive in its proportions and implications. ${ }^{1}$

Gularabulu, a collection of oral stories told by Paddy Roe and transcribed and edited by Stephen Muecke, is an important work in that possibly for the first time an attempt is made to present Aboriginal discourse as it is spoken rather than how the editor thinks it should be rendered into a written form. Stephen Muecke followed this work with another and perhaps more ambitious text in which he made use of the transcribed discourse of Paddy Roe, but within this volume the discourse is of secondary importance and becomes a signifier to the position of the Aborigine in modern Australia. Aboriginal discourse is captured. Paddy Roe the storyteller becomes discourse segments imprisoned within the standard English text of Stephen Muecke, and his country suffers the same fate in being captured within the graphics of Krim Benterrak. Paddy Roe thus becomes a simile of the Aborigine as convict and his country as land owned by the invader. Discourse signifies reality and Paddy Roe and his stories are segregated within the rigid walls of European theory. The text Reading the country ${ }^{2}$ can be read not as constructing a theory of nomadology as declared on the title page, but as Paddy Roe as discourse serving time under the gaze of European critics, Barthes and Foucault. The language, the discourse of the nomad loses its mobility, loses its freedom, and standard English, not content with being introduction or footnote, enters to share the body of the text. The Aboriginal discourse thus is a signifier to the reality of Aboriginal communities being penetrated and manipulated by European advisers. Furthermore, Paddy Roe as discourse has been collected and placed within this volume in much the same way as Aboriginal artefacts are placed in a museum.

Aboriginal discourse as calcification.

An observer visiting the Northwest of Western Australia will see that Paddy Roe and his people in the Kimberley, in Broome suffer as a calcified colonised society. This calcification may be read from many texts of anthropology. In other texts such as English and the Aboriginal child ${ }^{3}$ another and more covert aim may be read. This is the assimilation of Aboriginal

Colin Johnson, of the Bibbulmun people of Western Australia, is a poet, novelist, and lecturer in Black Australian Literature at the University of Queensland. His books include Wild cat falling, Long live Sandawarra and The song cycle of Jacky and selected poems. He is co-author of Before the invasion: Aboriginal life to 1788 .

1 Stephen Muecke in Roe 1983:v.

2 Benterrak, Muecke and Roe 1984.

3 Eagleson, Kaldor and Malcolm 1983. 
discourse into standard English. This urge to do away with, to replace Aboriginal discourse is also seen in such texts as Banggaiyerri, ${ }^{4}$ a so-called life story of Jack Sullivan. In such works Aboriginal discourse must be translated, that is assimilated completely into the standard English of white Australia. This attitude to Aboriginal discourse signifies an ideological position. Aborigines are to be forced into the majority culture. Assimilation on the discourse level signifies an ideological commitment to assimilation on the social level.

Opposed to this are the modes of traditional discourse and Aboriginal languages. But are these viable alternatives? Increasingly, traditional discourse is being made over into an artefact. It is becoming fossilised, and the young people are turning away from the remains. The languages of their communities are becoming objects of shame, ridiculous monuments of stone-age culture. This is only too evident in a work such as My country of the pelican dreaming. ${ }^{5}$ All effectiveness and social dynamism are monopolised by the coloniser's institutions. If an Aborigine needs help it is to them he applies, and if he does something wrong it is by them that he is punished - and if his story is to be written, it is to be written by the coloniser and in the coloniser's own discourse. Even the discourse of the educational system to which the Aborigine sends his children belongs to the coloniser, and what is learnt within such a system signifies the things of Europe rather than those of his country - though perhaps a few tokens of Aboriginality are thrown in as a goodwill gesture. Aborigines when they enter such a system are taken by the hand and escorted to their places. Children soon learn that they are there to be educated into a life-style and discourse that is not their own. A foreign culture is thrust upon them and they recite by rote words from a foreign tongue. If they fail to master the dominant discourse of standard English, they are relegated to the discourses of Kriol or Aboriginal English, and those who do achieve a fluency in standard English fall into a linguistic dualism. In the situation in which Aborigines find themselves this bilinguism is a necessity. Standard English is a condition for all culture, for all communication and progress, and is seen as the future discourse of all Aborigines. Thus Aboriginal languages are put on the defensive, as are the varieties of Aboriginal English which must be apologised for, or reconstructed, or translated, or explained. Rarely are they accepted. They are constantly under discussion and study. They are constantly under threat.

\section{Discourse under threat}

Separation between native language and cultural language is not peculiar to the colonised, but it cannot be compared to just any linguistic dualism. Possession of two languages is not merely a matter of having two tools, but is the participation in two psychical and cultural realms. Two worlds are symbolised; two discourses are in conflict, and it is the mother discourse or language of the colonised which is devalued. In 1986 a sign appeared in the sky with the launching of the AUSSAT communications satellite. It meant that it was now possible to flood the whole of Australia with the majority discourse of standard English.

This sign signifies the subordinate position of Aboriginal modes of discourse. These may be taught in a few schools, may be heard on a few radio programmes, but possession of them is not enough in Australia. If an Aboriginal person wants a job, wants to secure some sort of position, the dominant discourse must be mastered. Everyone knows this, and so the Abo- 
rigines themselves, especially the young, are discarding their languages. They feel ashamed of them, declare that they know them not, hang their heads as they mumble that they talk like everybody else.

If we take this into account when examining the life stories collected by Bruce Shaw ${ }^{6}$ there is little cause to wonder that Jack Sullivan and Grant Ngabidj surrendered their discourse to him. They had little choice. It was either this, or writing their own books, and their subordinate position made it difficult for them even to think of this; but if they had done so, it might have resulted in them becoming aware of their position in modern Australia. Of course, this never occurred, and so in the volumes produced by Bruce Shaw we find little comment on the political position of the Aborigines. It is only when we turn to books written by Aborigines with some control over their work, that the subordinate position of the Aborigines is examined. Thus writers such as Robert Bropho ${ }^{7}$ and Elsie Roughsey ${ }^{8}$ by keeping control over their work are able to question the white dominance directly. They to some degree manage to seize the dominant position for Aboriginal discourse.

When an Aborigine suddenly is confronted by a white person with a tape recorder, it is only natural for a self-censorship to come into play. The Aboriginal person conscious of his or her subordinate position is extremely careful to tell the white person what she or he expects to hear. The Aborigine suddenly becomes tongue-tied, suddenly hesitates as the past two hundred years of oppression weighs on his or her shoulders. He or she remembers the time when to open one's mouth, to speak the truth could and often did mean death. His culture is filled with accounts of men opening their mouths to receive in exchange for their words of defiance a bullet; her culture is filled with accounts of women being raped and murdered.

Until the advent of Robert Bropho and Elsie Roughsey, the only way, apart from sitting down with a recording white man or woman and giving him or her your words, was to write in standard English. Thus the Aboriginal writer had to waste a lot of his or her creative imagination and energy in acquiring a style acceptable to the readers of standard English. Even now, non-standard English needs words of apology. Thus Robert Bropho's book is foreworded by a publisher's note apologising for his Aboriginal English and Elsie Roughsey's book has an afterword explaining away her discourse. But this marks an advance, for in the past Aboriginal writers had to express themselves in a discourse not their own, that is they had to assimilate themselves into the majority discourse for publication. Even then, they found that they were not just writers or Australian writers, but Aborigines writing in standard English, and were not judged on merit. By writing, they exposed themselves to the contradictions set up by the assimilation policy, and found that there was really no assimilation, except for the wound in their souls.

\section{The dominant discourse is a dialect of power}

The majority culture for some time now has sought to image Aborigines in dubious productions termed 'autobiographies'. Often altruistic motives are given for producing these compromised volumes. A fine example of this genre is $I$, the Aboriginal, by Douglas

71980.

81984. 
Lockwood, ${ }^{9}$ who mined an Aboriginal man for source material. This is a journalistic production with the subject matter tightly controlled and rendered down into prose suitable for public consumption. I doubt that the $I$ of the story had any choice in the discourse used. Other Aborigines, usually sportspersons, for example Lionel Rose and Evonne Goolagong, are taken over and defined by journalists. Then there are the biographies, such as that of $\mathrm{Sir}$ Douglas Nicholls, ${ }^{10}$ written by people for a number of reasons, such as to show the white majority that the subject is exactly like one of them, or to serve as models for Aboriginal youngsters. Naturally, the role model is set out in standard English discourse as this is a prime requisite for Aboriginal achievement in Australia.

In the 1960 s, the taping of life stories (life histories) was popularised by the American social anthropologist, Oscar Lewis, who turned his tapes into best sellers, ${ }^{11}$ possibly with the help of judicious and thorough editing. The Australian anthropologist, Bruce Shaw, followed the American lead to produce three volumes. These are essentially anthropological texts extending the methods of American social anthropology to Australia. His attitude to Aboriginal discourse is discussed by him in the introductions to his texts. His justification for rewriting the texts, which we must remember are anthropological volumes published by the Australian Institute of Aboriginal Studies, is worth quoting:

Tampering with the original expressiveness worried me at first, until I realised that it was unrealistic to expect the general reader to wade through 200 pages written in the original style. ${ }^{12}$

Shaw's 'general reader' can only be read as a European. It is difficult to accept the text as being 'told to Bruce Shaw' when he has consciously failed to reproduce the Aboriginality of the discourse.

Stephen Muecke is at the other extreme. He is deeply conscious of Aboriginal discourse and takes pains to transcribe it accurately, but his volumes Gularabulu and Reading the country are flawed in that the discourse of Paddy Roe is barricaded between slabs of standard English. Paddy Roe thus is reduced to a discourse which is to be read by the European. Kriol or Aboriginal English is presented as an interesting artefact which may be measured and deciphered by the tools of European criticism.

It is noteworthy in these white productions that there is an absence of critical and political comment on the part of the subject. There is no analysis of Aboriginal-being-in-Australia, though, as I have written, a close reading does reveal that the text as a whole does signify the true position of the Aborigine in Australia.

\section{Subordinate discourse}

It is only when an Aborigine becomes a writer and turns toward putting his or her life story down, that we find a text different in discourse and subject matter. Elsie Roughsey wrote $A n$ Aboriginal mother tells of the old and the new, ${ }^{13}$ then watched it being edited, but there has not been the wholesale rewriting as practised by Bruce Shaw or the massive

91962.

101975 .

11 See for example Lewis 1965.

12 Shaw 1981:3.

131984. 
framing and intrusions of Stephen Muecke. Elsie retains control, as much as she is able, of her work, and this results in reflections on the Aboriginal-being-in-Australia.

I wondered so much about all this. We have drifted so far away from that life, and have gladly marched forward into that life that really is hurting us, to care not to go any further. ${ }^{14}$

When Aborigines write and put down their words, reflection and analysis enter, and although the immediacy of oral discourse is lessened, this in no way detracts from the Aboriginality of the text. We have but to compare Elsie's discourse with that of Shaw to realise the difference in feeling, and in reading such a text there is no sense of losing oneself on the tracks of the prose as Shaw would have us believe. Perhaps it is the act of writing itself, of consciously or unconsciously being in control of your voice which makes for a stronger narrative. In a sense to the Aborigine, writing is more important than being recorded in that it allows you to keep control of your material and tell it how you feel it should be told.

\section{Control of discourse signifies control of being}

We read the effect of this control in Robert Bropho's book The fringedweller. ${ }^{15}$ This is the least tampered with of Aboriginal life stories and is mercifully free of long forewords, introductions and afterwords explaining, conceptualising and doing all sorts of things to Aboriginal discourse in exactly the same way that the white people have been doing physically to Aboriginal people since the first European ships sailed along our shores.

\section{A discourse of Aboriginality}

Robert Bropho's text presents us with mixed signals. It is both a polemic and an autobiography. Robert Bropho as the Fringedweller expands his life outwards to encompass all fringedwellers. His text is not so much the life story of Robert Bropho, but of an entire people living on the fringes of white Australia. Community is foremost, and this is signified by the cover, which shows a family pressed together into a collective whole.

\section{The discourse of presentation}

The covers of the texts we have been discussing are significant. A reading discloses the state of Aboriginal-European relations in Australia. The cover of Reading the country is a reproduction of a painting by Krim Benterrak, a non-Aborigine. From it we read that the land is bounded, the horizon vague and indistinct, with a central image shaped like a prison. It reminds us of Elsie Roughsey's words:

We thought we were aiming for a better life to be treated fairly and equally. But as years were going out on us in our lives, we soon found we were rounded by wire nettings and fences, and we found living in this modern life, we had lost. 16

The covers of Bruce Shaw's books disclose a non-Aboriginality. The pelican illustrating the cover of My country of the pelican dreaming is a bird done in a naturalist style. It is only a bird, lacking a dreaming essence. Banggayerri's cover might belong to any story of a cattle station. A large male figure dominates the composition in medium close-up and below his chest

14 Roughsey 1984:235.

151980.

$161984: 234$. 
are the buildings of the station. There is no Aboriginality there. The male figure might be the founding patriarch of a cattle empire. If we contrast these two covers with that of Elsie Roughsey's text, immediately we are in the presence of Aboriginality. The cover is a reproduction of a painting by her husband, Dick Roughsey. It wraps the text around and shows a group of figures, a community or family standing on a jetty facing across a river towards the natural greenness of the far shore. The people are black and clad in European clothing. Three of the figures, whose backs are in the foreground, hold Aboriginal weapons. The only intrusion of Europeanness is the clothing and jetty. The foreground figures are the elders and they stand back while the younger people stand on the jetty over the river and gaze at the far bank. Immediately the question springs to mind: are they standing there attempting to read the future, or are they waiting for a European boat to ferry them across?

These covers point towards the inner text and are texts in themselves. From them we are able to read certain things: the essential whiteness of Muecke's book, the manipulated texts of the 'told-to' of Bruce Shaw; the confrontation of Roughsey's community with the future; and Robert Bropho's group solidarity. From the covers if we continue on to the texts, we are able to read the degrees of compromise presented in the discourse.

Biography and life history in the dominant mode of discourse, although utterly compromised as to their mode of presentation, perhaps do have a value as bound texts in signifying the position of Aborigines in modern Australia. The dominant discourse is a social marker signifying Aboriginal subordination, and perhaps this is all we might expect from such texts in which the voice of the Aborigine has been denied expression. It is only when the Aborigine as writer or story-teller retains his or her own discourse that we find an authenticity of presentation. For it is not only what is said that is important, but how it is said, especially in the case of Aborigines, who until recently were denied a voice and a discourse of their own.

\section{BIBLIOGRAPHY}

Benterrak, Krim, Stephen Muecke and Paddy Roe. Reading the country: introduction to nomadology. Fremantle, WA, 1984.

Bropho, Robert. Fringedweller, Sydney, 1980.

Clark, Mavis Thorpe. Pastor Doug: the story of Sir Douglas Nicholls, Aboriginal leader. Adelaide 1974. 1 st edn 1965.

Eagleson, Robert D., Susan Kaldor and Ian G. Malcolm. English and the Aboriginal child. Canberra, 1983. Lewis, Oscar. La vida. New York, 1965.

Lockwood, Douglas. I, the Aboriginal. Adelaide, 1962.

Roe, Paddy. Gularabulu, ed. Stephen Muecke. Perth, 1983.

Roughsey, Elsie (Labumore). An Aboriginal mother tells of the old and the new. Fitzroy, Vic., 1984.

Shaw, Bruce. Banggaiyerri: the story of Jack Sullivan. Canberra, 1983.

Countrymen: the life histories of four Aboriginal men as told to Bruce Shaw. Canberra, 1986.

My country of the pelican dreaming: the life of an Australian Aborigine of the Gadjerong, Grant

Ngabidj, 1904-1977, as told to Bruce Shaw. Canberra, 1981. 